\title{
New methods of efficiency evaluation of poultry subcomplex
}

\author{
I.S. Kondratenko*, and V.A. Blaginin \\ Ural State University of Economics, 620144 Yekaterinburg, Russia
}

\begin{abstract}
The political and economic situation in Russia and around Russia in recent years brings to the fore the most pressing issues, including the problem of food security of the country. The solution of this problem can be connected only with increasing the efficiency and competitiveness of the domestic agro-industrial complex. A special role in agro-industrial complex is played by the multiplier industries, to which the poultry subcomplex refers to. Evaluation of its effectiveness requires new approaches, coming from the fact that this subcomplex is a link of a sole chain - agro-industrial complex.
\end{abstract}

\section{Introduction}

The efficiency of a certain resource is due to the ratio of the maximum result and the minimum costs. Sometimes the maximum and minimum is replaced with optimality, that is, such a value that gives the best total. In the poultry subcomplex, this approach does not reflect the complete picture - and this experts opinion in the field of poultry farming is confirmed in practice. This criterion "does not allow to practically determine the extent to which the production resources available in the economy are used together because of the incommensurate factors of production" [1].

According to V.I. Nechayev and S.D. Fetisov, "economic efficiency of production of agricultural products means the highest level of labor productivity at maximum production from a unit of land area, that is, the efficiency criterion of agricultural production is characterized by the ratio of gross production to the costs of living and materialized labor" [1].

Undoubtedly, the main efficiency criterion of the poultry subcomplex is to maximize the profit of its constituent organizations. It reflects both the level of costs and generated revenue. Thus, in 2018 loss-making organizations in the crop and livestock industry amounted to $19.8 \%$, which is $0.6 \%$ less than in 2017 [2]. Despite the decline, the share of inefficient enterprises in agriculture is still high.

The main factor for achieving the efficiency of the poultry subcomplex is "the production of consumer values created by labor and satisfying certain needs of people or of every individual with their properties" [1].

\footnotetext{
* Corresponding author: kondratenko@usue.ru
} 
Among the estimated indicators [3] of a particular economic phenomenon, the efficiency assessment of the business entity functioning is considered to be the most difficult.

Following general scientific traditions, in most cases economic efficiency is considered as a ratio of effect and costs to achieve it:

$$
E_{\text {con.ef }}=\frac{E_{e}}{C}
$$

$E_{\text {con.ef }}$ - economic efficiency; $E_{e}$ - economic effect, rub.; C - costs, rub.

There is a significant variety of definitions of "economic efficiency." Thus, individual researchers determine efficiency as the maximum production result at the minimum of resource costs.

There is also such an approach when this category is represented in the form of the ratio of gross production to the costs of living and materialized labor.

$$
E_{\text {con.ef }}=\frac{G_{p r}}{C_{l . s l}}
$$

$E_{\text {con.ef }}$ - economic efficiency; $G_{p r}$ - gross product of the industry, rub; $C_{l . s l}$ - the costs of living and social labor, rub;

In the context of market relations, the ratio of profits maximization and minimum costs of capital and resources is prioritized, which should also be considered as an option for estimating economic efficiency.

$$
E_{\text {con.ef }}=\frac{\text { Max }_{\text {prof }}}{C_{\text {cap.r }}}
$$

$E_{\text {Con.ef }}$ - economic efficiency; $\mathrm{Max}_{\text {prof }}$ - maximum profit, rub; $C_{\text {cap.r }}$ - capital and resource costs, rub;

In relation to the poultry industry and poultry subcomplex under the embargo conditions and modernization of the industry, to evaluate the functioning effectiveness it is necessary to develop certain generalizing criteria of efficiency, as well as methodical approaches to the complex efficiency evaluation of the poultry subcomplex mechanism.

\section{Research}

Methodological approaches should take into account the internal state of the subcomplex, the multifactor influence of the external environment on its subjects, elements and components.

Consistency and complexity of efficiency evaluation of the poultry subcomplex, which together with other characteristics is an open system, exposed to external, both extreme and motivational factors.

Implementing methodological approaches of complex efficiency assessment of poultry subcomplex functioning we consider it necessary to develop a number of criteria:

$\mathrm{C} 1$ - criterion of economic efficiency;

$\mathrm{C} 2$ - criterion of social efficiency;

C3 - criterion of innovation efficiency (Figure 1).

Such criteria will serve as a kind of measure of economic efficiency and be specified through certain indicators (quantitative expressions). Thus, production, financial and economic indicators can be attributed to the criteria of economic efficiency of poultry subcomplex functioning evaluation.

Among the production indicators the following stand out:

- growth of production volumes; 
- preservation of young stock;

- feed conversion;

- egg yield of laying hens;

- average daily weight increment, etc.

Financial and economic indicators in assessing the effectiveness of poultry food complex are as follows:

- production cost;

- labor costs per $1 \mathrm{~kg}$ of poultry meat weight increment;

- costs for processing $1 \mathrm{~kg}$ of poultry meat;

- cost of $1 \mathrm{~kg}$ of feed;

- administrative expenses;

- selling prices;

- stock return;

- gross profit, the line can also be supplemented by a number of other significant indicators.

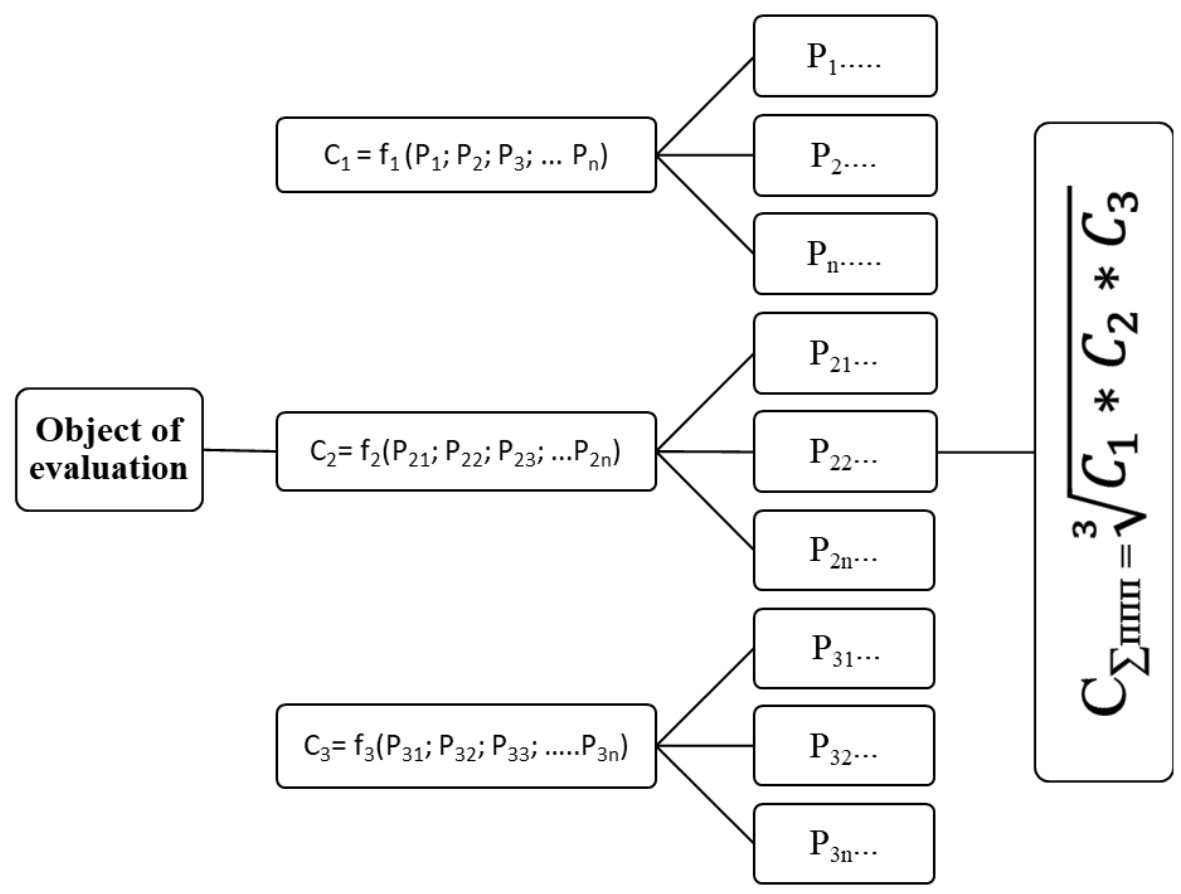

Fig. 1 - Model on principled approaches development to complex evaluation of poultry subcomplex functioning efficiency

We consider it appropriate to include the following criteria of social efficiency:

- the size and level of salary;

- level of personnel morbidity;

- personnel turnover of poultry subcomplex enterprises;

- observance of holiday schedules at the enterprise;

- existence of a bonus system, possibility of staff participation in income and profit distribution, etc. 
To the criteria of innovation and investment efficiency, in our opinion, the following should be included:

- availability of an innovative program;

- implementation of investments;

- payment of investments;

- investment objects and investment projects, etc.

In a formalized form, each of the criteria can be presented as follows:

$\mathrm{C} 1$ - criterion of economic efficiency;

$\mathrm{C} 2$ - criterion of social efficiency;

$\mathrm{C} 3$ - criterion of innovation and investment efficiency.

The cumulative (integral) criterion determining the efficiency of the poultry subcomplex functioning can be expressed through the following formula:

$$
C_{\sum P S C}=\sqrt[3]{C_{1} * C_{2} * C_{3}}
$$

$\mathrm{K}_{\Sigma \text { пाп }}$ - aggregate integral criterion; $\mathrm{C} 1=\mathrm{f} 1(\mathrm{P} 1 ; \mathrm{P} 2 ; \mathrm{P} 3 ; \ldots . . . \mathrm{Pn}) ; \mathrm{C} 2=\mathrm{f} 2(\mathrm{P} 21 ; \mathrm{P} 22$; P23;... P2n); C3= f3(P31; P32; P33;... P3n);

It should be emphasized that the number of criteria can be expanded, but everything depends on the purpose of the study. Our study sets a specific task related to the assessment of efficiency and competitiveness of the poultry subcomplex. We have developed three main criteria with a certain system of indicators, which allows to provide the necessary assessments of efficiency and competitiveness.

Each of the proposed indicators specifying a certain criterion can be calculated differently. Multiple options can be used:

a) the indicator is calculated as the ratio of actual to planned;

b) the indicator is calculated as the ratio of actual to normative value;

c) the indicator is calculated as the ratio of actual to regional average;

d) the indicator is calculated as the ratio of actual to that of the leader-competitor in the industry.

Based on the results of calculations, it will be possible to assess the effectiveness of planned indicators, the ratio of actual values with normative values, comparison with regional level or industry leader competitor.

\section{Results}

A comprehensive assessment of the PSC effectiveness will ensure the production of competitive products and the survival of market relations. As a result, a dual problem solution will be provided in the poultry subcomplex:

- conditions creation in the poultry subcomplex of AIC of the Russian Federation, which will help to create demand for poultry products and realize the needs of the domestic market, and if possible, certain segments of foreign markets;

- development of a support system for PSC enterprises aimed at increasing competitiveness and efficiency, based on monitoring the implementation of commitments made by the poultry farm.

However, the solution of these tasks is impossible without the state management of the poultry subcomplex, which is clearly coordinated with the management of the entire agroindustrial complex, which is a system of relation to the PSC. All elements of this system should work in coherence, only then will the synergistic effect be obtained. Deep analysis of the industry and evaluation of its effectiveness should be carried out taking into account opportunities to increase the competitiveness of the poultry subcomplex through innovative 
development. In this case, the proposed methodological approaches will contribute to the identification of promising enterprises capable of introducing innovations.

However, a full analysis and comprehensive evaluation of effectiveness is not possible without the accumulation of an appropriate database. Therefore, we propose that PSC enterprises should be required to disclose the cost of innovation and to allocate revenues generated by innovations. This may be an additional form sent to PSC enterprises from the Ministry of Agriculture of Russia or the Ministry of Economic Development. The latter option is preferable, as poultry subcomplex is interconnected not only with agriculture, but also with related industries. But an even better option would be to supplement accounting statements with an appropriate form that reveals the results of innovation activity. Only in this case efficiency and innovative potential of poultry subcomplex enterprises can be fully evaluated.

State regulation of the industry should evaluate not only the placement of poultry subcomplex enterprises, resources reserves and volumes and directions of cargo flows, but also socio-economic situation in the regions, including real incomes and solvent population demand based on a comprehensive assessment of the subcomplex efficiency. The result should be a closed cycle opposed to imports: fodder production, mineral additives, veterinary preparations - production of equipment and software for PSC — poultry cultivation for meat, egg - additional production (fluff and feather; organic fertilizers) deep raw materials processing — food production — wholesale and retail network. The domestic market needs to be adjusted based on average consumption of poultry products per capita.

However, at the same time state regulation of both agro-industrial complex of Russia and poultry subcomplex should be adjusted taking into account import substitution objectives. And, as it has been noted many times, this adjustment should be related to the development of innovative processes in the industry and the expansion of markets for poultry products. Simultaneity of these two processes is important because the market with traditional types of poultry meat is already almost saturated, and egg may soon reach saturation. However, the intersecting competition in the poultry industry, poultry meat and eggs production can lead to a deterioration of the situation and a reversal of the achievements obtained. If measures are not taken in time both by the State and by the PSC enterprises themselves, the domestic market's own provision may be reduced. In addition to competition, it is impossible to discount the poorly developed domestic breeding business, as well as epidemics outbreaks of bird flu, which claim hundreds of thousands of poultry heads, causing huge damage to economic entities, after which some of them find it difficult to recover.

Based on the evaluation of the PSC effectiveness, businesses capable of developing both economy class and premium exports to developed countries should be identified.

\section{References}

1. V.I. Nechaev, S.D. Fetisov, Economics of industrial poultry farming, 150 (2010)

2. Russia in numbers. 2019: Short coll.works, Rosstat, 244 (M., 2017)

3. M.M. Kislitsky, A.A. Chumachev, E.P. Gan, Agrifood policy of Russia, 8, 43 (2013)

4. V. Kravchenko, Meat market in Russia: results of 2019 and prospects (FSBI "Center of Agroanalytics", 2019)

5. A. Krylov, "Chickens don't peck" (Russian idiom for "rolling in money") Farming disaster in poultry: in 2018 the production of more than a dozen large Russian poultry farms were closed and drastically reduced, Meat portal, (2019) 
6. World Meat Market, International Independent Institute of Agrarian Policy, OEC, http: //image. rf/analytics/Mirovoj-rynok-masa

7. Meat market in Russia: results of 2019 and prospects, Meatinfo, https://meatinfo.ru. 